\title{
ON STEVIĆ-SHARMA OPERATOR FROM WEIGHTED BERGMAN-ORLICZ SPACES TO BLOCH-TYPE SPACES
}

\section{ZHITAO GUO}

Abstract. In this paper, we are devoted to investigating the metrical boundedness and metrical compactness of Stević-Sharma operator $T_{\psi_{1}, \psi_{2}, \varphi}$ from the weighted Bergman-Orlicz space $\mathscr{A}_{\alpha}^{\Phi_{p}}$ to Bloch-type space $\mathscr{B}^{\mu}$ and little Bloch-type space $\mathscr{B}_{0}^{\mu}$.

Mathematics subject classification (2020): Primary 47B38, secondary 47B33, 30H30.

Keywords and phrases: Stević-Sharma operator, metrical boundedness, metrical compactness, weighted Bergman-Orlicz space, Bloch-type space.

\section{REFERENCES}

[1] M. S. Al Ghafri, J. S. Manhas, On Stević-Sharma operators from weighted Bergman spaces to weighted-type spaces, Math. Inequal. Appl. 23, 3 (2020), 1051-1077.

[2] S. ChARPENTIER, Composition operators on weighted Bergman-Orlicz spaces on the ball, Complex Anal. Oper. Theory 7, 1 (2013), 43-68.

[3] C. C. COWEn AND B. D. MACClueR, Composition operators on spaces of analytic functions, Studies in Advanced Mathematics. CRC Press, Boca Raton, 1995.

[4] Z. Guo, L. LiU, Y. SHU, On Stević-Sharma operator from the mixed norm spaces to Zygmund-type spaces, Math. Inequal. Appl. 24, 2 (2021), 445-461.

[5] Z. Guo, Y. SHu, On Stević-Sharma operators from Hardy spaces to Stević weighted spaces, Math. Inequal. Appl. 23, 1 (2020), 217-229.

[6] Z. JIANG, Generalized product-type operators from weighted Bergman-Orlicz spaces to Bloch-Orlicz spaces, Appl. Math. Comput. 268, (2015), 966-977.

[7] Z. JiAnG, On a product-type operator from weighted Bergman-Orlicz space to some weighted type spaces, Appl. Math. Comput. 256, (2015), 37-51.

[8] Z. JiAng, On Stević-Sharma operator from the Zygmund space to the Bloch-Orlicz space, Adv. Difference Equ. 2015, 228 (2015), 12 pp.

[9] Z. JIANG, X. WANG, Products of radial derivative and weighted composition operators from weighted Bergman-Orlicz spaces to weighted-type spaces, Oper. Matrices 12, 2 (2018), 301-319.

[10] H. LI, Z. GUO, On a product-type operator from Zygmund-type spaces to Bloch-Orlicz spaces, J. Inequal. Appl. 2015, 132 (2015), 18 pp.

[11] S. Li, S. STEvić, Composition followed by differentiation from mixed-norm spaces to $\alpha$-Bloch spaces, Mat. Sb. 199, 12 (2008), 117-128.

[12] S. LI, S. STEVIĆ, Products of composition and integral type operators from $H^{\circ}$ to the Bloch space, Complex Var. Elliptic Equ. 53, 5 (2008), 463-474.

[13] S. Li, S. STEVIĆ, Products of Volterra type operator and composition operator from $H^{\infty}$ and Bloch spaces to the Zygmund space, J. Math. Anal. Appl. 345, 1 (2008), 40-52.

[14] S. Li, S. Stević, Products of composition and differentiation operators from Zygmund spaces to Bloch spaces and Bers spaces, Appl. Math. Comput. 217, 7 (2010), 3144-3154.

[15] S. LI, S. STEVIĆ, Generalized weighted composition operators from $\alpha$-Bloch spaces into weightedtype spaces, J. Inequal. Appl. 2015, 265 (2015), 12 pp.

[16] Y. LiU, Y. Yu, On a Stević-Sharma operator from Hardy spaces to the logarithmic Bloch spaces, J. Inequal. Appl. 2015, 22 (2015), 19 pp. 
[17] Y. LIU, Y. YU, Products of composition, multiplication and radial derivative operators from logarithmic Bloch spaces to weighted-type spaces on the unit ball, J. Math. Anal. Appl. 423, 1 (2015), 76-93.

[18] K. Madigan, A. Matheson, Compact composition operator on the Bloch space, Trans. Amer. Math. Soc. 347, 7 (1995), 2679-2687.

[19] S. OHNo, Products of composition and differentiation between Hardy spaces, Bull. Austral. Math. Soc. 73, 2 (2006), 235-243.

[20] B. Sehba, S. Stević, On some product-type operators from Hardy-Orlicz and Bergman-Orlicz spaces to weighted-type spaces, Appl. Math. Comput. 233, (2014), 565-581.

[21] B. Sehba, S. Stević, Relations between two classes of real functions and applications to boundedness and compactness of operators between analytic function spaces, Math. Inequal. Appl. 19, 1 (2016), 101-115.

[22] A. K. Sharma, Products of composition multiplication and differentiation between Bergman and Bloch type spaces, Turkish J. Math. 35, 2 (2011), 275-291.

[23] A. K. Sharma, S. D. Sharma, Composition operators on weighted Bergman-Orlicz spaces, Bull. Austral. Math. Soc. 75, 2 (2007), 273-287.

[24] A. Shields, D. Williams, Bounded projections, duality, and multipliers in spaces of analytic functions, Trans. Amer. Math. Soc. 162, (1971), 287-302.

[25] S. STEvić, Composition operators from the weighted Bergman space to the nth weighted spaces on the unit disc, Discrete Dyn. Nat. Soc. Art. 2009, Art. ID 742019 (2009), 11 pp.

[26] S. STEvić, Products of composition and differentiation operators on the weighted Bergman space, Bull. Belg. Math. Soc. Simon Stevin 16, 4 (2009), 623-635.

[27] S. Stević, Composition followed by differentiation from $H^{\infty}$ and the Bloch space to nth weightedtype spaces on the unit disk, Appl. Math. Comput. 216, 12 (2010), 3450-3458.

[28] S. STEVIĆ, Composition operators from the Hardy space to the $n$th weighted-type space on the unit disk and the half-plane, Appl. Math. Comput 215, 11 (2010), 3950-3955.

[29] S. STEVIĆ, Weighted differentiation composition operators from the mixed-norm space to the nth weighted-type space on the unit disk, Abstr. Appl. Anal. 2010, Art. ID 246287 (2010), 15 pp.

[30] S. STEVIĆ, Z. JiAng, Weighted iterated radial composition operators from weighted Bergman-Orlicz. spaces to weighted-type spaces on the unit ball, Math. Methods Appl. Sci. 44, 11 (2021), 8684-8696.

[31] S. Stević, A. K. Sharma, On a product-type operator between Hardy and $\alpha$-Bloch spaces of the upper half-plane, J. Inequal. Appl. 2018, 273 (2018), 18 pp.

[32] S. Stević, A. K. Sharma, A. Bhat, Essential norm of products of multiplication composition and differentiation operators on weighted Bergman spaces, Appl. Math. Comput. 218, 6 (2011), 23862397.

[33] S. Stević, A. K. Sharma, A. Bhat, Products of multiplication composition and differentiation operators on weighted Bergman space, Appl. Math. Comput. 217, 20 (2011), 8115-8125.

[34] S. Stević, A. K. Sharma, R. KRishan, Boundedness and compactness of a new product-type operator from a general space to Bloch-type spaces, J. Inequal. Appl. 2016, 219 (2016), 32 pp.

[35] S. Stević, S. UeKI, Weighted composition operators from the weighted Bergman space to the weighted Hardy space on the unit ball, Appl. Math. Comput. 215, 10 (2010), 3526-3533.

[36] S. WANG, M. WAng, X. Guo, Differences of Stević-Sharma operators, Banach J. Math. Anal. 14, 3 (2020), 1019-1054.

[37] R. YonedA, The composition operators on weighted Bloch space, Arch. Math. (Basel) 78, 4 (2002), 310-317.

[38] Y. YU, Y. LIU, On Stević type operator from $H^{\infty}$ space to the logarithmic Bloch spaces, Complex Anal. Oper. Theory 9, 8 (2015), 1759-1780.

[39] F. Zhang, Y. LiU, On a Stević-Sharma operator from Hardy spaces to Zygmund-type spaces on the unit disk, Complex Anal. Oper. Theory. 12, 1 (2018), 81-100. 